\title{
Evaluation of the Functional Impression Technique with Various Impression Materials on the Surface Topography of Dental Stone Casts and Their Effect on Retention
}

\author{
Manal R. Alammari \\ Department of Oral and Maxillofacial Prosthodontics, King Abdulaziz University, Jeddah, KSA \\ Email: malammari@kau.edu.sa
}

How to cite this paper: Alammari, M.R. (2018) Evaluation of the Functional Impression Technique with Various Impression Materials on the Surface Topography of Dental Stone Casts and Their Effect on Retention. Open Journal of Stomatology, 8 , 258-270.

https://doi.org/10.4236/ojst.2018.87024

Received: June 26, 2018

Accepted: July 21, 2018

Published: July 24, 2018

Copyright $\odot 2018$ by author and Scientific Research Publishing Inc. This work is licensed under the Creative Commons Attribution International License (CC BY 4.0).

http://creativecommons.org/licenses/by/4.0/

(c) $\underset{\mathrm{EY}}{\mathrm{C}}$ Open Access

\begin{abstract}
Background: The accuracy of the final prosthesis is affected by the final impression technique and master cast production. The aim of the present study was to evaluate the effect of the functional impression technique with various impression materials on the surface characteristic of dental stone casts and their clinical effect on the retention of complete dentures. Method: Specimens of three impression materials/stone casts were fabricated. The specimens of the impression materials/stone casts were divided into three equal groups (I, II, and III). The impression materials used were as follows: tissue conditioner group (I), zinc oxide (ZEO) (group II) and poly (vinyl siloxane) (PVS) (group III). Cylindrical split aluminium moulds were designed to receive the impression materials and the stone mixture. The surface roughness of the stone cast specimens of the three groups (I, II, and III) was measured with a surface profilometer and analyzed by a scanning electron microscope. A clinical study included five severely resorbed mandibular edentulous alveolar ridges and edentulous maxillary arches. Each subject received three heat-cured acrylic resin dentures, fabricated using the functional impression technique. The three dentures were identical except for the different impression materials used from Groups I, II and III. The retentive force of each denture for each subject was measured. Result: The results of this study revealed that the mean value of surface roughness of the stone cast surface of group I was higher than group II and group III. A statistically significant difference was observed in surface roughness and the retentive dislodging force between the three studied groups. Although using a tissue conditioner as a functional impression material led to a high level of surface roughness and good retention, it could not
\end{abstract}


produce the same smooth surface quality of PVS or ZEO. These data were supported by SEM analysis. The complete dentures for these patients require important oral and denture hygiene care. Conclusion: Complete dentures made using functional impression technique with PVC as a final impression material are more comfortable, retentive and stable.

\section{Keywords}

Impression Techniques, Impression Materials, Surface Roughness, Scanning Electron Microscope and Retention of Complete Denture

\section{Introduction}

The prevalence of edentulism has increased in low- and middle-income countries due to sociodemographic factors, poor lifestyle habits and inferior quality of healthcare services. Complete dentures are one of the treatment modalities for edentulous patients [1] [2].

Impression making is an essential step in the fabrication of complete dentures. The success of complete dentures depends on selecting the impression materials, the accuracy of the impression and the impression technique. Impression making in total edentulism is important, not only for denture retention and stability but also for the mucosa status, which should be maintained without any distortions [3]. The oral cavity is a unique environment that promotes the formation, accumulation and deposition of biofilm on the surfaces of artificial prostheses. Prostheses with smooth surfaces are desirable to prevent plaque and calculus accumulation and to improve aesthetics [4] [5].

Surface defects or irregularities may be caused by using an improper impression technique. Various techniques have been used to make complete denture impressions, including mucostatic, mucocompressive, selective pressure, functional, and neutral zone impressions. Final impression materials for complete denture construction include the following: zinc oxide eugenol pastes (ZOE), elastomeric impression materials and tissue conditioners [6] [7].

A current survey showed that $97 \%$ of prosthodontists use ZOE as their material of choice for final impressions. ZOE is mucostatic and easily adapts to the soft tissues due to its water-based system. It therefore provides detailed reproduction of the soft tissues without causing displacement. A major drawback of ZOE is that it becomes rigid after setting and therefore is not capable of recording undercuts, which limits its application to non-undercut areas [3] [8].

In the last decade, many studies have suggested using newer elastomeric materials for final impressions to replace older and more traditional materials. The newer materials have better mechanical and physical properties [9].

Tissue conditioners (TCs) are considered an ideal functional impression material and can be applied temporarily to the fitting surface of a denture to allow 
for a more equal load distribution, thus permitting the mucosal tissues to return to their normal position.

TC can also be applied to the fitting surface of an old denture where the patient is asked to wear the denture for a period of time up to $48 \mathrm{hrs}$, and then a stone cast is poured within the impression to construct new dentures [9] [10] [11] [12].

The major part of the denture is constructed outside of the mouth from a precise replica of the denture-bearing tissues called a cast. The cast is made from an impression of the edentulous mouth [13] [14] [15].

Dental technicians can perform a series of procedures on the model to construct individualized dentures, cast crowns, or orthodontic appliances. The model must have an accurate and smooth surface. The surface roughness of models affects the surface roughness of the cast restorations; therefore, the fit or retention of the prosthesis may be affected [16].

The accuracy of master casts is dependent on numerous factors, including the water/powder ratio, vacuum versus hand mixing, and the type of dental stone and its compatibility with impression materials. The accuracy of the final prosthesis may be affected by factors such as the final impression technique and master cast production [17]. Accordingly, the purpose of the present study was to evaluate the effect of the functional impression technique with various impression materials on the surface characteristic of the dental stone cast and to clinically evaluate their effects on the retention of complete dentures.

\section{Materials and Methods}

The present study was conducted in two parts: laboratory and clinical studies.

\subsection{Laboratory Study}

A total of 45 specimens of three impression materials/stone cast were considered to determine the surface roughness of the dental stone cast made from these impression materials. The specimens for the impression materials/stone casts were divided into three equal groups (I, II, and III), with fifteen in each group. The impression materials used were tissue conditioner (TC) (group I) (Coe-Comfort, GC America, Inc, IL, USA), zinc oxide (group II) (ZOE) paste (Cavex Outline, Impression pste; Cavex Holland BV, Holland) and poly (vinyl siloxane) (PVS, Aquasil, Dentsply) impression material (group III). Cylindrical split aluminium moulds (50 mm length $\times 30 \mathrm{~mm}$ diameter) were fabricated. The metallic mould consists of a lower hollow ring (A) designed to receive the impression materials and an upper ring (B) adjusted to receive the stone mixture to ensure intimate contact at the impression material/cast interface (Figure 1).

Each impression material was mixed according to the proportion indicated by the manufacturer. The mixture was poured into the cylindrical mould (A), and a glass slab was placed on top of the ring to ensure a smooth surface, while the material set. Then, the specimens were poured with dental stone type III (Golden, 


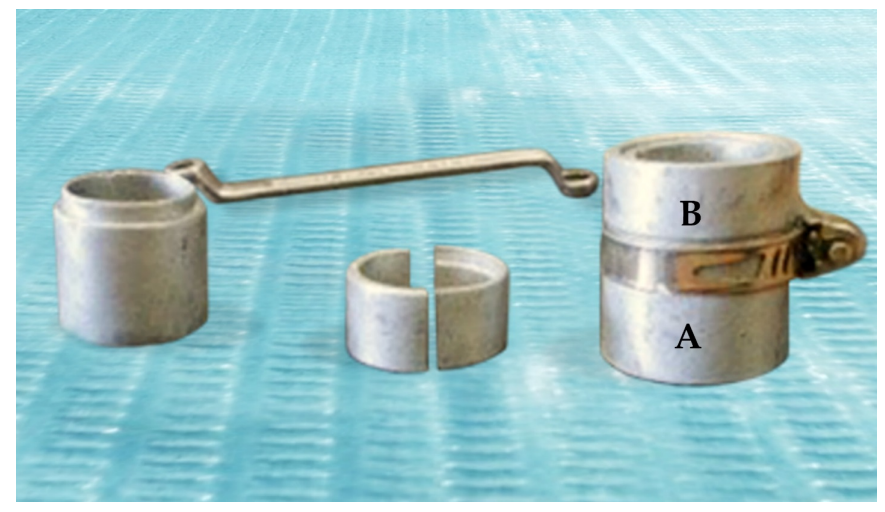

Figure 1. Cylindrical mould, lower ring (A) for the impression material and upper ring (B) to receive the stone material and finally the stone mould.

WhipMix Corporation) mixed in a water/powder ratio as recommended by the manufacturer. The mixing was performed mechanically under a vacuum for 15 seconds. Then, the mixture was poured into the split mould (B) and placed on a vibrator. The mould was overfilled, covered with another glass slab and allowed to set in the air for 60 minutes. Then, the stone casts were separated from the impression materials.

The specimens of group II and group III were stored in an incubator at $37^{\circ} \mathrm{C}$ for 15 minutes, while tissue conditioner specimens were stored in a water bath in an incubator at $37^{\circ} \mathrm{C}$ for $24 \mathrm{hrs}$.

\subsection{Surface Roughness Measurements}

The surface roughness $(\mathrm{Ra}, \mu \mathrm{m})$ of the stone cast specimens of the three groups (I, II, and III) was determined with a surface profilometer (SurftestSJ-201P, Mitutoyo America Corporation). The stylus of the meter was passed across and perpendicular to the abraded surface of the specimen under constant pressure. Three measurements were obtained from different areas of each specimen, and then, the average of these readings of the surface roughness was calculated and expressed as Ra value, which is defined as the average vertical deviation along the surface of the specimen measured in micrometres $(\mu \mathrm{m})$.

\subsection{Surface Analysis by Scanning Electron Microscope (SEM)}

SEM was analyzed to investigate the surface topography of stone cast specimens of the three groups (I, II, and III) using a scanning electron microscope (SEM: JSM-6360LA, JEOL, Tokyo, Japan). Specimens were prepared by sputter-coating with gold using a sputtering device (SPI sputter coater structure, probe USA) to obtain high-resolution electronic imaging, and the cross-sectional area was then examined at 500X magnification.

\subsection{Clinical Study}

\section{Ethical considerations}

Ethical approval for the study was obtained from the Ethics Committee of 
King Abdulaziz University. The conventional ethical considerations for conducting research (preserving anonymity, ensuring confidentiality and obtaining informed consent) were complied with (Proposal No 057-17). At the beginning of the study, written informed consent was obtained. Study conducted from September 2017 until March 2018.

Five completely edentulous male patients, aged 65 years old, married, low to middle income with severely resorbed mandibular alveolar ridges (Atwood's order V) [18] and edentulous maxillary arches were selected from the clinic of the Prosthodontic Department. The patients had several ill-fitting and unstable dentures that moved during swallowing and speech. They were healthy, free from any systemic disease with an acceptable level of oral hygiene. They were not subjected to chemotherapy or radiotherapy.

At the beginning, each subject received three heat-cured acrylic resin dentures (Vertex RS Dentimex Netherlands), fabricated using the functional impression technique. The three dentures were identical except for different impression materials used in each group (I, II, and III). The retentive force of each denture for each subject was measured.

\subsection{Denture Fabrication (Functional Impression Technique)}

Primary impressions of both edentulous arches were made using irreversible hydrocolloid impression material. Custom trays were fabricated on the preliminary maxillary cast using visible light-cured resin (VLC, Tru Tray Sheet, Dentsply). Maxillary border moulding was performed using a low fusing compound, and the final impression was made using zinc oxide eugenol paste impression material. The maxillary cast of each patient was duplicated to obtain three more maxillary casts. Record bases were fabricated on the maxillary casts of each patient.

On the primary mandibular cast, record bases with occlusal rims were fabricated. Jaw relations were performed to record appropriate horizontal and vertical dimensions.

Denture group (I): The tissue conditioning material was applied on the tissue surface of the mandibular denture base, and the patient was asked to close the mouth in the pre-recorded vertical dimension and perform various functional movements, such as puffing, blowing, whistling, and smiling. The tissue conditioner material was left intraorally for at least 24 hours before pouring a dental stone cast. Denture group (II): Zinc oxide eugenol paste impression material was applied on the tissue surface of the mandibular denture base using the closed mouth technique, and the patient was asked to perform various functional movements. Denture group (III): PVS impression material was used, and the same technique was followed.

The final impression for each denture was poured with type III dental stone. Maxillary and mandibular occlusal rims were fabricated on the master casts, and jaw relations were recorded. Mounting was performed on a semi-adjustable ar- 
ticulator. Teeth arrangement and wax try-in were performed in the patient's mouth. Flasking, processing, finishing and polishing of dentures were performed using conventional methods. The dentures were inserted into the patient's mouth and assessed for retention stability, support and occlusion.

\subsection{Measurement of Retention Force}

The patient was seated in an upright position in the dental chair with the head resting firmly against the head rest. With self-cure acrylic resin, a metallic hook of the load cell of an electronic scale (Weiheng Electronic Scale. SelectechGuangdond, China, Mainland) was secured in the polished mid-lingual surface of each mandibular denture, and the pull end of the digital force gauge device was connected to it. The retentive force was measured after wearing the denture (time of insertion) for 30 minute intervals between tests for each denture of the three groups. An upward pull was applied in the vertical direction and parallel to the path of insertion until the denture base was dislodged from the patient's mouth, and the dislodgment force was recorded in Newton (N) for each patient (three readings for each patient with the three types of the mandibular dentures in group (I, II, and III) were recorded). The data were collected for statistical analysis. The results were evaluated, and the retention of mandibular dentures fabricated from the functional impression technique with various impression materials was compared.

\subsection{Statistical Analysis of the Data}

Data were analysed by two-way analysis of variance (ANOVA). Means and standard deviations were determined for each group. ANOVA with repeated measures (post hoc Tukey) was used to compare more than two groups. Significance of the obtained results was judged at the $5 \%$ level.

\section{Results}

Table 1 presents the mean value of surface roughness of the stone cast surface made from the tissue conditioner of group I, which had the highest values (1.77 $\pm 0.08 \mu \mathrm{m})$, while group III had the lowest values $(1.06 \pm 0.08 \mu \mathrm{m})$, followed by group II $(1.10 \pm 0.05 \mu \mathrm{m})$.

Data were subjected to two-way analysis of variance (ANOVA), which showed a significant difference among the three studied groups $(\mathrm{F}=314.454)$ at the $5 \%$ level.

According to statistical analysis using a post hoc Tukey test between groups, there was a significant difference in surface roughness between group I and II ( $P$ $=0.001)$ and between group I and group III $\left(p_{2}=0.001\right)$. No significant differences were observed between group II and group III.

The mean force required to dislodge the dentures is shown in Table 1. The mean value of retention dislodging force of group I was $17.24 \pm 1.19 \mathrm{~N}$, of group II was $13.57 \pm 2.27 \mathrm{~N}$ and of group III was $13.59 \pm 1.91 \mathrm{~N}$. The ANOVA test 
Table 1. Comparison of the mean value of surface roughness $(\mathrm{Ra}, \mu \mathrm{m})$ of the stone cast surface and the retentive dislodging force $(\mathrm{N})$ of mandibular dentures in the three studied groups.

\begin{tabular}{|c|c|c|c|c|c|}
\hline \multicolumn{6}{|c|}{ Surface roughness of stone cast $(\mu \mathrm{m})$} \\
\hline Parameter & Group I & Group II & Group III & F & $\mathbf{P}$ \\
\hline Mean \pm SD & $1.77 \pm 0.08$ & $1.10 \pm 0.05$ & $1.06 \pm 0.08$ & & \\
\hline $\begin{array}{l}\text { Sig. between } \\
\text { groups }\end{array}$ & \multicolumn{3}{|c|}{$p_{1}<0.001^{\star}, p_{2}<0.001^{\star}, p_{3}=0.375$} & $314.454^{*}$ & $<0.001^{*}$ \\
\hline \multicolumn{6}{|c|}{ The measurement of retention dislodging force } \\
\hline Parameter & Group I & Group II & Group III & F & $\mathbf{P}$ \\
\hline Mean \pm SD & $17.24 \pm 1.19$ & $13.57 \pm 2.27$ & $13.59 \pm 1.91$ & $19.721^{*}$ & $<0.001^{*}$ \\
\hline $\begin{array}{l}\text { Sig. between } \\
\text { groups }\end{array}$ & \multicolumn{3}{|c|}{$p_{1}<0.001^{\star}, p_{2}<0.001^{\star}, p_{3}=1.000$} & & \\
\hline
\end{tabular}

F and $p$ values for ANOVA test; Sig. between groups was performed using a post hoc test (Tukey); ${ }^{*}$ : Statistically significant at $p \leq 0.05$.

showed that there was a significant difference in retention between the three studied groups $(\mathrm{F}=19.721)$ at the $5 \%$ level, where group I showed the highest mean value of retention followed by group III, and group II showed the lowest mean value.

A post hoc Tukey test was used for comparison between groups, and there was a significant difference in the retention between group I and II $(P=0.001)$ and between group I and group III $\left(p_{2}=0.001\right)$. No significant differences were observed between group II and group III.

\section{SEM Analysis}

The crystalline configuration of group III and group II (Figure 2(b) and Figure 2(c)) showed prismatic crystals, regularly oriented, smooth in shape, densely packed without porosities, while group I (Figure 2(a)) showed a prismatic crystal, less densely packed with porosities.

\section{Discussion}

Several impression materials are used in the prosthodontic clinic. Zinc oxide eugenol (ZOE) impression material may be selected due to its inherent accuracy and propensity to distribute pressure equally. ZOE is mucostatic and provides detailed reproduction of the soft tissues without causing displacement of the soft tissues, but its application is limited to non-undercut areas [13] [19]. ZOE has a high flow property that facilitates a speedy reaction due to rosin constitution. PVS impression material may be selected due to its detailed reproduction, high dimensional stability, ease of handling, high elastic recovery [3] [20] [21] and its ability to construct multiple casts from an impression [13] [22] [23].

Tissue conditioner is used as a functional impression due to its rheological 


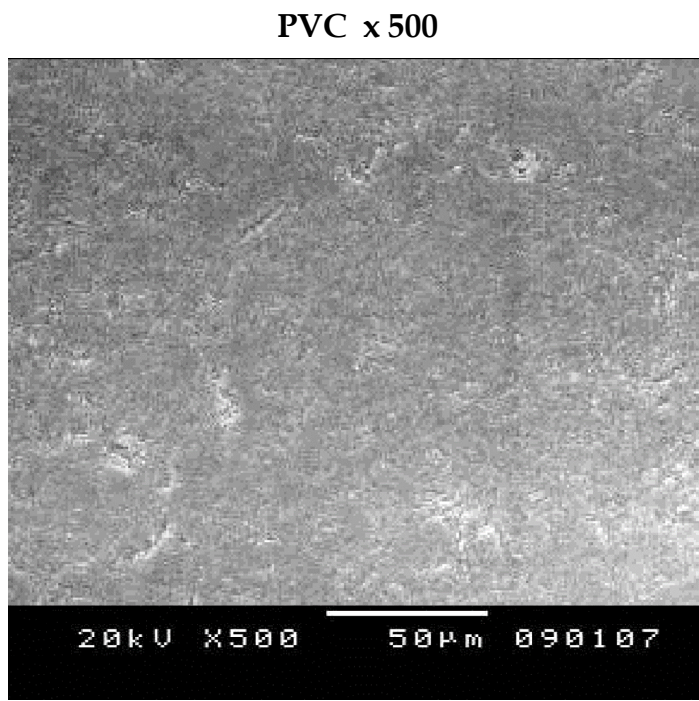

(a)

Zinc oxide $x 500$

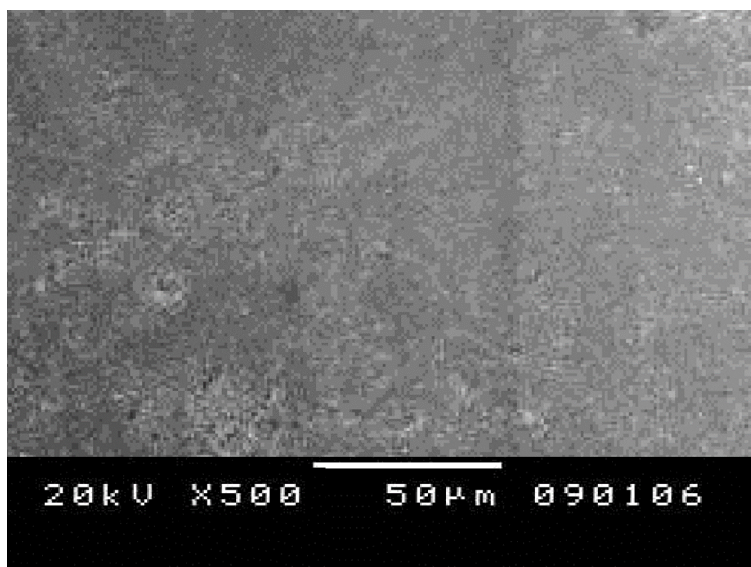

(b)

Tissue conditioner $x 500$

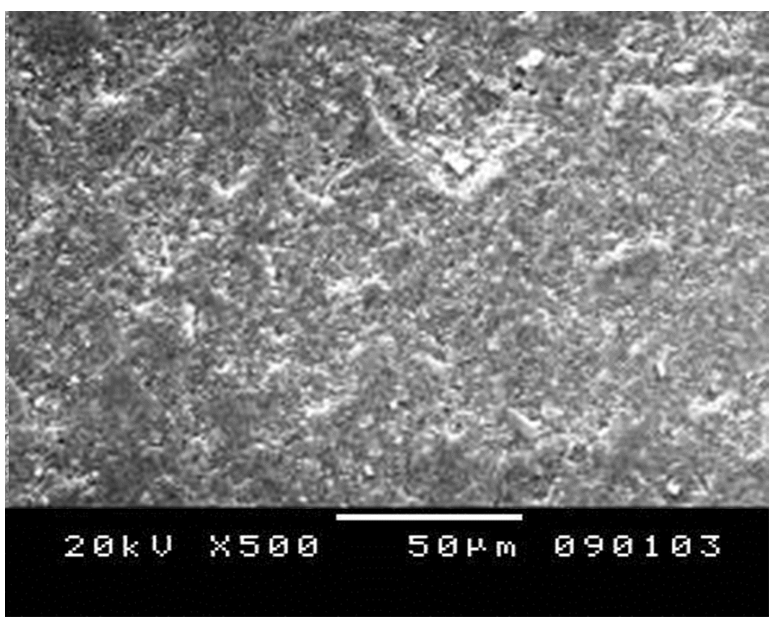

(c)

Figure 2. (a, b, c): The stone cast specimens were observed under SEM at 500X magnification. (a) Group I; (b) Group II; (c) Group III. 
properties, dimensional stability, ability to reproduce details and undercuts, durability and compatibility with dental stone [13].

The surface roughness of dental materials was investigated in the present study as this characteristic affects surface free energy and the rough surfaces of dental materials cause a high surface free energy resulting in more microbial plaque formation. Thus, surface roughness of dental prosthetic materials is important because these materials are in contact with oral tissues, the most critical area of the oral environment, and the materials are related to the long-term clinical performance. The smooth surfaces of dental materials may cause easy surface cleaning and less microbial accumulation. Surface roughness measures the irregularities present on the dental stone cast and provides information on the morphology of the surface, such as a porous or textured surface, and is measured using a scanning electron microscope (SEM) [20] [21] [24] [25] [26].

Our results revealed that the mean surface roughness of group I using a tissue conditioner left for $24 \mathrm{hrs}$ was increased, which might be related to changes in the quality of the surface moulds due to a loss of a plasticizer and ethyl alcohol and water absorption. The loss of these soluble materials (ethanol and plasticizer) increases the number of tiny bubbles on the mould surface and, subsequently, the casts [27] [28] [29]. This result was supported by SEM images of surface roughness of the stone cast.

The mean values of surface roughness of the stone cast of group III were the lowest. This result may be due to the use of PVS, which is hydrophilic due to extrinsic additions that improve oral tissue and gypsum wettability when the impression and cast pouring are performed. A surface characteristic evaluation of the present study confirmed by SEM revealed no voids or bubbles on the stone cast surface [6] [15] [28] [30].

The functional impression technique was recommended in this study over the conventional impression technique, which results in a distorted impression. The functional technique is preferable for a severely resorbed alveolar ridge as it is difficult to obtain good retention and stability of complete dentures, and the presence of muscular activity due to muscular insertion near the crest of the ridge induces displacement of the denture. Drago concluded that a mandibular denture base constructed from the closed mouth technique was more retentive than the open mouth technique. The closed-mouth technique saves time and has a lower chance of under or overextension of movement preferred by the patient as the pressure applied by the patient during the impression is the same as the pressure applied while occluded [14] [31].

The tissue conditioner materials were left intraorally for at least 24 hours before pouring a dental stone cast to make an accurate impression and avoid distortion of the impression surface caused by insufficient elastic recovery of the materials [32].

Our results revealed that the highest mean value of retention was obtained with group I and group III. These results may be due to the nature of these im- 
pression materials as they have viscoelastic properties, offering high elastic recovery, flexibility on removal of the impression from the mouth and can withstand various stresses upon removal from tissue undercuts while maintaining dimensional stability and integrity. Additionally, their consistency and longer setting time enable the operator to perform functional movements while taking impressions [33] [34].

The hydrophilic properties of the PVS impression reduced marginal voids and distortion in the impressions and improved the quality of gypsum dies [35].

There was a significantly increased retention in group I compared to group III and group II, which may be due to a rough or porous surface that encourages saliva droplets to become entrapped in these pores. Porous surface may cause a mechanical irritation of the underlying soft tissues and adherence of microbes to the fitting surface. Therefore, it is advisable to ensure a smooth surface and stress the importance of oral and denture hygiene for the patients [36] [37] [38].

\section{Conclusion}

Based on the laboratory and clinical results obtained from this study, it can be concluded that success of complete dentures principally depends on exactness of impression and the functional impression technique is necessary to achieve retention in complete denture for geriatric patients who had severely resorbed and deformed ridges. Measuring surface roughness values is required to evaluate the surface quality of this impression technique of the various impression materials and their influence on the dental stone cast. Complete dentures made using functional impression technique with PVC as a final impression material are more comfortable, retentive and stable.

\section{Declaration}

Availability of supporting data is available on request from the corresponding author.

\section{Conflicts of Interest}

The authors declare no conflicts of interest regarding the publication of this paper.

\section{References}

[1] Nordenram, G., Davidson, T., Gynther, G., Helgesson, G., Hultin, M., Jemt, T., et al. (2013) Qualitative Studies of Patients' Perceptions of Loss of Teeth, the Edentulous State and Prosthetic Rehabilitation: A Systematic Review with Meta-Synthesis. Acta Odontologica Scandinavica, 71, 937-951. https://doi.org/10.3109/00016357.2012.734421

[2] Peltzer, K., Hewlett, S., Yawson, A.E., Moynihan, P., Preet, R., Wu, F., et al. (2014) Prevalence of Loss of All Teeth (Edentulism) and Associated Factors in Older Adults in China, Ghana, India, Mexico, Russia and South Africa. International Journal of Environmental Research and Public Health, 11, 11308-11324. https://doi.org/10.3390/ijerph111111308 
[3] Hadjieva, H. and Dimova, M. (2005) Selective Pressure Impression Methods for Total Dentures by Patients with Loose and Hypermobile Mucosa on the Alveolar Ridges. Journal of IMAB, 11, 51-53.

[4] Coulthwaite, L. and Verran, J. (2007) Potential Pathogenic Aspects of Denture Plaque. British Journal of Biomedical Science, 64, 180-189. https://doi.org/10.1080/09674845.2007.11732784

[5] Teles, F.R., Teles, R.P., Sachdeo, A., Uzel, N.G., Song, X.O., Torresyap, G., et al. (2012) Obituary: Abram I. Chasens, DDS. Journal of Periodontology, 83, 1. https://doi.org/10.1902/jop.2012.121001

[6] Johnson, G.H. (2001) Impression Materials. In: Craig, R.G. and Powers, J.M., Ed., Restorative Dental Materials, 11th Edition, Elsevier, St Louis, 348-368.

[7] Rameez, M., Razi, Sh., Farhan, F., Kumar, B. and Rashid, H. (2018) Clinical Implications of Elastomeric Impression Materials Used for Complete Denture Construction. Dentistry \& Medical Research, 6, 19-23. https://doi.org/10.4103/dmr.dmr_10_17

[8] Noort, R.N. (2007) Introduction to Dental Materials. 3rd Edition, Mosby Elsevier, London, UK.

[9] Anusavice, K.J. (2006) Philips Science of Dental Materials. 11th Edition, Elsevier, New York, USA.

[10] Murata, H., Narasaki, Y., Hamada, T. and McCabe, J.F. (2006) An Alcohol-Free Tissue Conditioner-A Laboratory Evaluation. Journal of Dentistry, 34, 307-315. https://doi.org/10.1016/j.jdent.2005.07.005

[11] Chander, S., Hill, M., Moore, D. and Morrow, L. (2007) Tissue Conditioning Materials as Functional Impression Materials. European Journal of Prosthodontics and Restorative Dentistry, 15, 67-71.

[12] Murata, H., Kawamura, M., Hamada, T., Saleh, S., Kresnoadi, U. and Toki, K. (2001) Dimensional Stability and Weight Changes of Tissue Conditioners. Journal of Oral Rehabilitation, 28, 918-923. https://doi.org/10.1046/j.1365-2842.2001.00736.x

[13] Hanif, A., Khan, J. and Bangash, MFK. (2014) Impression Technique and Materials Usd for Fabrication of Complete Denture: A Survey. Pakistan Oral \& Dental Journal, 34, 170-173.

[14] Yadav, B., Jayna, M., Yadav, H., Suri, Sh., Phogat, S. and Madan, R. (2014) Comparison of Different Final Impression Techniques for Management of Resorbed Mandibular Ridge: A Case Report. Case Reports in Dentistry, 2014, Article ID: 253731. https://doi.org/10.1155/2014/253731

[15] Faria, A.C.L., Rodrigues, R.C.S., Macedo, A.P., da Gloria Chiarello de Mattos, M. and Ribeiro, R.F. (2008) Accuracy of Stone Casts Obtained by Different Impression Materials. Brazilian Oral Research, 22, 293-298. https://doi.org/10.1590/S1806-83242008000400002

[16] Chang, Y., Yu, C., Liang, W., Tu, M. and Chen, S. (2016) Comparison of the Surface Roughness of Gypsum Models Constructed Using Various Impression Materials and Gypsum Products. Journal of Dental Sciences, 11, 23-28.

https://doi.org/10.1016/j.jds.2012.11.002

[17] Yuzbasioglu, E., Kurt, H., Turunc, R. and Bilir, H. (2014) Comparison of Digital and Conventional Impression Techniques: Evaluation of Patients' Perception, Treatment Comfort, Effectiveness and Clinical Outcomes. BMC Oral Health, 14, 10. https://doi.org/10.1186/1472-6831-14-10 
[18] Atwood, D.A. (1971) Reduction of Residual Ridges: A Major Oral Disease Entity. The Journal of Prosthetic Dentistry, 26, 266-279. https://doi.org/10.1016/0022-3913(71)90069-2

[19] Jacobson, T.E. and Krol, A.J. (1983) A Contemporary Review of the Factors Involved in Complete Dentures. Part II: Stability. The Journal of Prosthetic Dentistry, 49, 165-172. https://doi.org/10.1016/0022-3913(83)90494-8

[20] Haghi, H.R., Asadzadeh, N., Sahebalam, R., Nakhaei, M. and Amir, J.Z. (2015) Effect of Denture Cleansers on Color Stability and Surface Roughness of Denture Base Acrylic Resin. Indian Journal of Dental Research, 26, 163-166. https://doi.org/10.4103/0970-9290.159149

[21] Roque, A.C., Bohner, L.O., de Godoi, A.P., Colucci, V., Corona, S.A. and Catirse, A.B. (2015) Surface Roughness of Composite Resins Subjected to Hydrochloric Acid. Brazilian Dental Journal, 26, 268-271. https://doi.org/10.1590/0103-6440201300271

[22] Rao, S., Chowdhary, R. and Mahoorkar, S. (2010) A Systematic Review of Impression Technique for Conventional Complete Denture. The Journal of Indian Prosthodontic Society, 10, 105-111. https://doi.org/10.1007/s13191-010-0020-2

[23] Petrie, C.S., Walker, M.P. and Williams, K. (2005) A Survey of U.S. Prosthodontists and Dental Schools on the Current Materials and Methods for Final Impressions for Complete Denture Prosthodontics. Journal of Prosthodontics, 14, 253-262. https://doi.org/10.1111/j.1532-849X.2005.00051.x

[24] Fasbinder, D.J. and Neiva, G.F. (2016) Surface Evaluation of Polishing Techniques for New Resilient CAD/CAM Restorative Materials. Journal of Esthetic and Restorative Dentistry, 28, 56-66. https://doi.org/10.1111/jerd.12174

[25] Țălu, Ş., Stach, S., Klaić, B., Mišić, T., Malina, J. and Čelebić, A. (2015) Morphology of Co-Cr-Mo Dental Alloy Surfaces Polished by Three Different Mechanical Procedures. Microscopy Research and Technique, 78, 831-839.

https://doi.org/10.1002/jemt.22547

[26] Özarslan, M.M., Büyükkaplan, U.Ş., Barutcigil, Ç., Arslan, M., Türker, N. and Barutcigil, K. (2016) Effects of Different Surface Finishing Procedures on the Change in Surface Roughness and Color of a Polymer Infiltrated Ceramic Network Material. The Journal of Advanced Prosthodontics, 8, 16-20. https://doi.org/10.4047/jap.2016.8.1.16

[27] Vafaei, F.F., Heidari, S.B., Saleh, S., Ansari, A. and Khazaei, A.S. (2012) Evaluation of the Effect of a Tissue Conditioner on Surface Roughness of Dental Stone. Avicenna Journal of Dental Research, 4, 49-58.

[28] Murata, H., Chimori, H., Hong, G., Hamada, T. and Nikawa, H. (2010) Compatibility of Tissue Conditioners and Denture Cleansers: Influence on Surface Conditions. Dental Materials Journal, 29, 446-453. https://doi.org/10.4012/dmj.2009-135

[29] Wilson, J. (1992) In Vitro Loss of Alcohol from Tissue Conditioners. The International Journal of Prosthodontics, 5, 17-21.

[30] Chee, W.W. and Donovan, T.E. (1992) Polyvinyl Siloxane Impression Materials: A Review of Properties and Techniques. Journal of Prosthetic Dentistry, 68, 728-732. https://doi.org/10.1016/0022-3913(92)90192-D

[31] Drago, C.J. (2003) A Retrospective Comparison of Two Definitive Impression Techniques and Their Associated Post Insertion Adjustments in Complete Denture Prosthodontics. Journal of Prosthodontics, 12, 192-197. https://doi.org/10.1016/S1059-941X(03)00082-2 
[32] Murata, H., Hong, G., Li, Y.A. and Hamada, T. (2005) Compatibility of Tissue Conditioners and Dental Stones: Effect on Surface Roughness. Journal of Prosthetic Dentistry, 93, 274-281. https://doi.org/10.1016/j.prosdent.2004.12.011

[33] Hamalian, T.A., Nasr, E. and Chidiac, J.J. (2011) Impression Materials in Fixed Prosthodontics: Influence of Choice on Clinical Procedure. Journal of Prosthodontics, 20, 153-160. https://doi.org/10.1111/j.1532-849X.2010.00673.x

[34] Perakis, N., Belser, U.C. and Magne, P. (2004) Final Impressions: A Review of Material Properties and Description of a Current Technique. International Journal of Periodontics and Restorative Dentistry, 24, 109-117.

[35] Re, D., De Angelis, F., Augusti, G., Augusti, D., Caputi, S., D’Amario, M., et al. (2015) Mechanical Properties of Elastomeric Impression Materials: An in Vitro Comparison. International Journal of Dentistry, 2015, Article ID: 428286.

[36] Sharma, S. (2010) Effect of Surface Texture of Intaglio Surface on Denture Retention-A Comparative Analysis in Vivo. Journal of the Indiana Dental Association, 4, 313-316.

[37] Yildirim, M.S., Hasanreisoglu, U., Hasirci, N. and Sultan, N. (2005) Adherence of Candida albicans to Glow-Discharge Modified Acrylic Denture Base Polymers. Journal of Oral Rehabilitation, 32, 518-525. https://doi.org/10.1111/j.1365-2842.2005.01454.x

[38] Gupta, R., Luthra, R.P. and Kumar, N. (2015) A Comparative Analysis of Retention of Denture Bases without and after Surface Treatment of Basal Surface with Different Sizes of Alumina Particles-An in Vivo Study. Journal of Advanced Medical and Dental Sciences Research, 3, 102-108. 